\title{
9
}

\section{Self-Determination in Positive Education}

\author{
Michael L. Wehmeyer, Sung Hyeon Cheon, Youngsun Lee, \\ and Matthew Silver
}

In 2004, pollsters with the Gallup Youth Survey asked U.S. teenagers to select the words that "best described how you usually felt at school". Options included challenged, interested, encouraged, excited, supported, appreciated, and happy. What were the top two words they selected? Bored (selected by half of these teenagers) and tired (selected by $42 \%$ ). Only $31 \%$ of these teens said they were happy or challenged, $22 \%$ said they were interested, and a mere $16 \%$ said that they were encouraged or excited. Unfortunately, over a decade later, little has changed. The cover story of a 2017 Harvard Graduate School of Education Magazine entitled Bored Out of Their Minds discussed a series of German studies over the past decade showing that student boredom was rampant, and it was related to lower test scores, which in turn, increased boredom (Jason, 2017). Boredom has been linked to helplessness and depression, anxiety, impulsiveness, and loneliness (Center on Addiction, 2003).

M. L. Wehmeyer (凶)

University of Kansas, Lawrence, KS, USA

e-mail: wehmeyer@ku.edu

S. H. Cheon

Korea University, Seoul, South Korea

Y. Lee

Ewha University, Incheon, South Korea

M. Silver

University College London, London, UK 
Why is education failing so many young people? We suggest that this is due in part to the ongoing paradigms of pedagogy grounded in teacher-driven instruction, undermining the self-determined motivations and energies of young learners. This chapter examines the primary theoretical frameworks that have driven educational interventions focused on self-determination and overviews several interventions derived from these theories.

\section{From Teacher-Directed Pedagogy to Self-Determined Learning}

Most people, and certainly almost all educators, are familiar with the word pedagogy. Pedagogy, they would probably say, refers to the practice of teaching - the methods that are used by teachers to promote learning in their students. A pedagogue is an educator, or as we interpret it today, someone who educates children. The word pedagogy comes from the Greek words pais ( $\pi \alpha \tilde{i} \varsigma)$, meaning child, son, or daughter, and ágo ("丷 $\gamma \omega)$, meaning leader. Together they form paidagōgia ( $\pi \alpha \iota \alpha \alpha \gamma \omega \gamma(\alpha)$ ), or, as it came to mean in ancient Greece, the office of a child's tutor. From the Greek root words, a pedagogue is a person who leads children. It is unidirectional: educators teaching students.

Teacher-directed learning continues to dominate many educational practices today. Consider the typical vocabulary for what happens in schools. Synonyms for educate include train, instruct, lecture, discipline, drill, direct, tutor, and edify. Even the less authoritative synonyms - coach, develop, enlighten, foster-imply that it is the adult who does something to the child. Pedagogy refers, essentially, to teacher-directed instruction. Yet the high levels of student boredom and disengagement with learning suggest a mismatch of pedagogy with student interests and needs. There is a need to go beyond teacher-directed pedagogy to more autonomous forms of learning.

\section{Andragogy}

We know how to do this better with adults. As early as the 1960s and 1970s, the field of adult education stressed the importance of andragogy rather than pedagogy in adult learning. There are obvious etymological similarities to these words, with the familiar ágo $(\alpha \chi \alpha \omega)$ meaning leader. The Greek $\alpha \nu \delta \rho$ (andr-) means man, so andragogy derives from to the now gender-insensitive notion of leading or teaching man. In implementation, however, andragogy, or as it came to be referred to, self-directed learning, reflects the importance 
of self-direction, rather than teacher-direction, in adult education. Psychologist Malcolm Knowles, who originated the term andragogy, observed that "individuals who take the initiative in learning, learn more things, and learn better, than do people who sit at the feet of teachers possibly waiting to be taught" (Knowles, 1975, p. 14).

Self-direction in learning presumes that learners are driven by a sense of curiosity, that experiences are resources that should be exploited to maximize learning, and that learners who are motivated internally will learn more effectively. Adult education theorists have expanded the ideas associated with andragogy, dividing self-direction in learning into two dimensions. The first, self-directed learning, refers to the process in which the learner engages to plan, implement, and evaluate learning. The second dimension, learner self-direction, focuses on the "learner's desire or preference for assuming responsibility for learning" (Brockett \& Hiemstra, 2012, p. 24). Responsibility refers to the notion of learner autonomy, rather than to an obligation or requirement to adhere to some rule. Responsibility as autonomy means that:

One can and does set one's own rules, and can choose for oneself the norms one will respect. In other words, autonomy refers to one's ability to choose what has value, that is to say, to make choices in harmony with self-realization .... to be free from all exterior regulations and constraints. (Chene, 1983, p. 39)

Personal autonomy as used in learner self-direction refers to "a broad disposition toward thinking and acting autonomously in all situations" (Candy, 1992, p. 101). Candy lists the qualifications for an autonomous person as someone who (p. 125):

- Conceives of goals and plans,

- Exercises freedom of choice,

- Uses the capacity for rational reflection,

- Has will power to follow through,

- Exercises self-restraint and self-discipline, and

- Views himself or herself as autonomous.

These characteristics are important for students as well as adults if they are to become more self-directed learners. The lesson from adult education and the ideas forwarded through andragogy is that learning has to be situated in learner autonomy and choice. 


\section{Heutagogy}

Just as changing educational contexts and demands require a shift to positive education and personalized learning today, the demands of online learning, the introduction of new technologies, and the need for greater self-direction have resulted in the need for another step in self-direction in adult learning. Blaschke (2012) observed that:

Pedagogical, even andragogical, educational methods are no longer fully sufficient in preparing learners for thriving in the workplace, and a more selfdirected and self-determined approach is needed, one in which the learner reflects upon what is learned and how it is learned and in which educators teach learners how to teach themselves. (p. 57)

That next step in a more self-directed learning approach is referred to by the term heutagogy, from the Greek عú $\rho \eta \mu \alpha$, which means discovered. Heutagogy suggests that importance of discovered learning, or, more commonly, self-determined learning. Blaschke (2012) notes that "in a heutagogical approach to teaching and learning, learners are highly autonomous and selfdetermined and emphasis is placed on development of learner capacity and capability with the goal of producing learners who are well-prepared for the complexities of today's workplace" (p. 56).

Self-determined learning incorporates practices in self-directed learning, but the instructor "fully relinquishes ownership of the learning path and process to the learner, who negotiates learning and determines what will be learned and how it will be learned" (p. 59). While much of the research on self-determined learning has occurred in adult education, we suggest that it is both relevant for and at times already is used in child and adolescent education. Specifically, in early, primary, and secondary education, a focus on self-determined learning has emerged from research and practice focused on issues pertaining to motivation and self-determination.

\section{Self-Determination in Positive Psychology}

There are two theoretical frameworks pertaining to self-determination that have driven most of the research and intervention development in the application of self-determination to the educational context and self-determined learning: Self-Determination Theory and Causal Agent Theory. 


\section{Self-Determination Theory}

Far and away the most visible framework of the self-determination construct arising from psychology is Self-Determination Theory (SDT), formulated by Edward Deci and Richard Ryan. Readers of this text will likely be familiar with SDT and due to the voluminous amount of research on SDT, this chapter will provide only a cursory overview (cf. Ryan \& Deci, 2017 for a detailed review). SDT is "an empirically based, organismic theory of human behaviour and personality development" (Ryan \& Deci, 2017, p. 3). SDT is comprised of six sub-theories (i.e., basic psychological needs theory, causal orientations theory, goal contents theory, organismic integration theory, relational motivation theory, cognitive evaluation theory), providing a "comprehensive macro-theory that details the origins and outcomes of human agentic action" (Adams, Little, \& Ryan, 2017, p. 47).

At its core, SDT is a theory of motivation focused on identifying social conditions that facilitate or hinder human flourishing and to identify "factors, both intrinsic to individual development and within social contexts, that facilitate vitality, motivation, social integration, and wellbeing" (Ryan \& Deci, 2017, p. 3). The theory attempts to explain how biological, social, and cultural conditions either enhance or undermine the inherent human needs for autonomy, competence, and relatedness.

SDT presumes that "humans are active organisms, motivated to assimilate and integrate knowledge and capacities in both their physical and social environments" (Adams et al., 2017, p. 47). SDT proposes three basic psychological needs-autonomy, competence, and relatedness; the fulfilment of which leads to autonomous (i.e., acting with a sense of full endorsement and volition) versus controlled (i.e., acting on the basis of a desire for external rewards or fear of punishment) motivation, optimal growth, and positive developmental outcomes. Autonomous actions are those that are self-endorsed, and congruent with one's values and interests (Vansteenkiste, Niemiec, \& Soenens, 2010). The need for autonomy is met when a person experiences choice and acts volitionally and, consequently, sees themselves as the origin of their actions. Competence refers to a person's need to perceive oneself as effective within environments (Deci \& Vansteenkiste, 2004). It does not refer to skills or skill levels; the need for competence is met when one perceives oneself as being competent and mastering activities and tasks (Deci, Ryan, \& Guay, 2013). The need for relatedness is met when people feel connected with other people, when they feel a sense of social belonging, and when they feel that they care for others and are cared for by others (Ryan $\&$ Deci, 2017). 
Unlike most motivation theories, SDT differentiates motivation into autonomous and controlled types, with types of motivation on a continuum from extrinsic to intrinsic: amotivation, external regulation, introjected regulation, identified regulation, integrated regulation, and intrinsic motivation. External regulation refers to actions that are extrinsically motivated and have strictly an external perceived locus of causality. Introjected regulation refers to actions performed due to self-administered rewards or punishments. Identified regulation refers to actions that align with personally valued goals, but still might be externally regulated. That is, the locus of causality remains external, but the alignment with personally valued goals make such actions more autonomous and self-determined. Integrated regulation refers to actions in which the person has internalized the values of the task as consistent with his or her own intrinsically motivated actions. And intrinsic regulation is internally motivated action, arising from one's own values and interests. Satisfaction of the three basic psychological needs mentioned previously is a foundational concept to SDT and considered essential for maintaining intrinsic motivation and the self-regulation of extrinsic motivations. SDT posits that autonomy-supportive social contexts enhance intrinsic motivation, while controlling social environments, often characterized by external rewards, thwart or reduce intrinsic motivation and action compelled by such motivation.

SDT has been applied across a broad range of domains (cf. Ryan \& Deci, 2017), including education, some of which will be reviewed subsequently that suggest that it is critical that classroom environments support competence, relatedness, and autonomy (Frederic, Ratelle, \& Chanal, 2008; Niemiec \& Ryan, 2009). This research has shown that autonomous motivation is linked to the student's engagement in academic tasks and their academic achievement. Establishing autonomy-supportive classrooms (see below for further discussion), involves creating learning spaces that maximize student involvement and self-determined learning and minimize teachercontrolled actions. Autonomy-supportive teachers spend more time listening to their students, as well as giving them time to work through problems and discover solutions. In these classrooms, students have meaningful roles in setting expectations, feel safe to explore and take risks, are supported to solve problems, set personal goals, and are responsible for monitoring and evaluating their progress.

In many ways, competence- and relatedness-supportive teaching and classrooms are built upon the foundation of autonomy supports and, indeed, most of the research on SDT in educational contexts has been in relation to autonomy-supportive teaching and classrooms. Ryan and Deci (2017) 
explained that it is "not that the need for autonomy is in any way more important than the needs for relatedness or competence" but that "in most settings having support for autonomy as a contextual factor plays a critical role in allowing individuals to actively satisfy all of their needs" (p. 247). Students obviously need to feel competent within school environments and contexts. One element of providing competency supports in classrooms is to ensure that students have an optimal challenge in relation to learning goals. That is, the content or task is difficult enough to challenge the student, but not so difficult as to thwart success. Also, performance versus mastery goals differently impact perceived competence. Mastery goals are goals that one volitionally adopts to improve one's knowledge, skills, or abilities. Performance goals are goals that tend to be comparative, looking at one's performance in contrast or compared with others' performance (or some form of a standard). Mastery goals have been shown to improve both academic performance and enhance wellbeing (Wehmeyer \& Zhao, 2020).

Relatedness-supportive teaching simply involves efforts that facilitate student feelings of connection and relatedness. Importantly, "relatedness is deeply associated with a student feeling that the teacher genuinely likes, respects, and values him or her" (Niemiec \& Ryan, 2009, p. 139). That is one of the benefits of autonomy-supportive teaching: when students perceive that teachers are autonomy-supportive, they are more likely to also believe that they are cared for and cared about. Further, relatedness supports involve more than creating a caring relationship between a student and a teacher: relationships among students matter as well.

\section{Causal Agency Theory}

A second theoretical framework that has driven work in promoting and explaining the development of self-determination is Causal Agency Theory, which arose from the work of Richard DeCharms on intrinsic motivation. DeCharms (1968) noted that:

Man's primary motivational propensity is to be effective in producing changes in his environment. Man strives to be a causal agent, to be the primary locus of causation for, or the origin of, his behavior; he strives for personal causation. (p. 269)

In the early 1990s, efforts in the field of special education to improve life outcomes for young people with disabilities turned a focus to issues of self-determination, drawing from research in SDT and DeCharms' notion of 
causal agency (Wehmeyer, 1992; Wehmeyer, Kelchner, \& Richards, 1996). These efforts sought to develop interventions and supports that enabled young people to become causal agents in their lives. One of the outcomes of these efforts was Causal Agency Theory (Wehmeyer, 2004; Wehmeyer \& Mithaug, 2006), which in recent years was updated to incorporate the expanding research in SDT and positive psychology (Shogren et al., 2015). Being a causal agent in one's life implies that one makes or causes things to happen in their life. Acting in a self-determined manner, thus, indicates that people make or cause things to happen in their own lives, rather than someone or something else making them act in specific ways. Self-determined action is goal oriented, driven by preferences and interests, and ultimately serves to enable people to enhance the quality of their lives (Shogren et al., 2015).

Causal Agency Theory was proposed to facilitate an understanding of the development of self-determination and, thus, drive educational interventions to promote self-determination and self-determined learning. The theory defined self-determination as:

A dispositional characteristic manifested as acting as the causal agent in one's life. Self-determined people (i.e., causal agents) act in service to freely chosen goals. Self-determined actions function to enable a person to be the causal agent in his or her life. (Shogren et al., 2015, p. 258)

As is the case with SDT, Causal Agency Theory is situated within human agentic theories that state that action is self-caused, and that people have an underlying desire to be the origin of their own behaviour. The theory proposes three essential characteristics of self-determined action-volitional action, agentic action, and action-control beliefs-that enable people to act as a causal agent in their lives, the performance thereof which leads to the development of self-determination. Volitional action refers to self-initiated actions that enable a person to act autonomously and to engage in selfgoverned action. Such actions refer to the means by which something is done or achieved; they are self-directed and goal focused. When they act agentically, self-determined people identify pathways that lead to specific ends or cause or create change. The identification of pathways, or pathways thinking, is a proactive, purposive process. Agentic action involves self-regulated and self-directed action that enables a person to progress towards freely chosen goals. Agentic actions involve actions that enable people to sustain action towards a goal. Action control beliefs refer to acting based upon the beliefs that one has what it takes to achieve freely chosen goals. People who have such beliefs see a link between their actions and the outcomes they desire. 
To account for these beliefs and actions, Causal Agency Theory incorporates basic tenets of Action-Control Theory (Little, Hawley, Henrich, \& Marsland, 2002), which posits three general beliefs associated with the causal action sequence:

control expectancy [beliefs], which refers to the relation between agent and ends, meaning that individual's expectancy about their capability to achieve a given goal or end; means-ends beliefs, which represent the relation between means and ends; and agency beliefs, [which] refer to an individual's beliefs of what means they are capable of utilizing when the self acts as an agent. (Chang, Adams, \& Little, 2017, p. 285)

That is, people who are self-determined believe that they have the means (skills, knowledge, abilities) to set and achieve a goal and that if they attempt to do so, they will be successful.

\section{The Development of Self-Determination}

Wehmeyer and colleagues (2017) proposed that self-determination develops as an adaptive outcome of a person's response to threats to and opportunities for autonomy, competence, and relatedness in one's environment. These threats and opportunities energize a causal action sequence that involves volitional and agentic action, as framed by Causal Agency Theory, as a means for a person to remain autonomous, competent, and maintain meaningful relationships, as emphasized by SDT. These volitional and agentic action responses are mediated by action-control beliefs (Mumbardó-Adam, GuàrdiaOlmos, \& Giné, 2018). So, from early in childhood onward, humans are motivated to act volitionally and utilize a causal action sequence involving volitional and agentic action mediated by action-control beliefs that enables them to act as a causal agent in their lives. Repeated experiences of causal agency, in turn, enable a person to meet basic psychological needs for, particularly, autonomy and competence, and result in enhanced self-determination.

Young people who have repeated experiences of acting as the causal agent in their lives become self-determined young people. Such experiences usually involve addressing small, day-to-day problems. So, for example, a young person may want to take a course in an area about which they are passionate about but may seem frivolous to their parents. It is through the process of negotiating with their parents to satisfy their desire to take the course and to address the parents' concern about the utility of the course that the young person can implement actions that enable them to act more autonomously, 
learn and practice skills that promote causal agency, and, over time, become more self-determined.

Describing a course for the development of self-determination is important so as to understand how to promote self-determination across the life course. It is through these types of experiences that young people become self-determined and it is important that teachers provide opportunities that enable young people to meet their psychological needs for autonomy, competence, and relatedness and to provide opportunities for young people to learn the skills and actions that enable them to act as causal agents in their lives. The next section examines interventions to promote autonomy and self-determination.

\section{Creating Autonomy-Supportive Classrooms}

Johnmarshall Reeve and colleagues (Reeve, 2002, 2012; Reeve \& Cheon, 2014; Reeve, Ryan, \& Deci, 2018) have identified a variety of factors that might lead to and result from autonomy supportive classrooms and teaching. This research has studied teacher-student interactions that promote the intrinsic motivation of students and, in turn, has led to the development of interventions to promote autonomy-supportive approaches to teaching. Reeve (2002) summarized research exploring the practices of autonomysupportive teachers and determined that they avoided being directive, praised mastery, avoided criticizing students, provided prompts rather than giving answers directly, responded reliably to student-generated questions, and communicated with the perspective of the student in mind. Reeve summarized this literature by categorizing autonomy-supportive teachers as being responsive, flexible, and motivating by generating interest, whereas controlling teachers tended to emphasize being in charge, shaping students towards specific answers, emphasizing non-standardized evaluation, and motivating through pressure. Importantly, this literature suggests that autonomysupportive classrooms are communities in which students take meaningful roles in setting classroom rules, feel safe to explore and take risks, engage in problem-solving activities, set personal goals, and take responsibility for monitoring their own progress towards those goals.

Chang, Fukuda, Durham, and Little (2017) further identified important characteristics of autonomy-supportive teachers: 
- Communicate frequently to clarify expectations and acknowledge students' feelings and to ensure that students know what is expected of them and do not have to depend upon the teacher to direct learning.

- Provide multiple opportunities for students to choose from, considering the relevance of activities to students' interests and values

- Do not rely on controlling events and experiences, such as competitions or evaluations.

- Encourage and support students to participate actively, rather than being passive observers/absorbers.

- Emphasize student self-direction and active involvement in generating, delivering, and consuming information and content.

- Provide informational feedback that is constructive but positive.

- Provide structured guidance that clearly states expectations and the student's role in meeting those expectations and supports students to plan for learning and action.

When teachers are autonomy-supportive, they can adopt students' perspective and provide them with choices, display patience for students' self-paced learning, communicate with a tone of understanding, provide meaningful rationales for requests, accept and acknowledge students' negative feelings, and use informational or invitational language (Reeve \& Cheon, 2020). Autonomy-supportive classrooms are learning environments in which students are motivated to act and engage in self-determined learning (Chang, Fukuda, Durham, and Little, 2017; Reeve, 2002).

In contrast, when the classroom structure is developed in a controlling manner, students' motivation and engagement can be undermined (Cheon, Reeve, \& Song, 2019; Cheon, Reeve, \& Vansteenkiest, 2020; Grolnick \& Pomerantz, 2009; Mouratidis, Lens, \& Vansteenkiste, 2010). And yet too often, the structure that teachers provide in classrooms is delivered in a more controlling manner. This is due in part to the general structure of schools (e.g., classroom goals, school-wide rules, statements of expectations, adherence to standardized testing), which are often controlling in nature, and impact upon how both teachers and students see their roles and responsibilities in the classroom. While these structures are well-intentioned, it can lead teachers (often unconsciously) to configure their classrooms in ways that are more controlling. For instance, teachers might develop rules with contingent/tangible rewards or punishment, expectations with conditional rewards, and classroom goals, guidance, or corrective feedback with teacher-prescribed ways. While these structures might meet the needs of the teachers to present 
information and lead the child, they can undermine student self-determined ways.

Notably, by structuring classrooms and practices in ways that are autonomy supportive, it can also support students' needs for competence and relatedness. For example, creating autonomy-supportive classrooms involves building learning spaces that emphasize student involvement and self-direction and minimize teacher-controlled actions, thus facilitating the promotion of student perceptions of competence. Autonomy-supportive teachers spend more time listening to their students, as well as giving them time to work through problems and discover solutions. Again, this has the added benefit of promoting student perceived competence and in establishing relationships based upon respect for student choice and voice that enhance student perceptions of relatedness (Ryan \& Deci, 2017).

There are clear benefits of autonomy-supportive environments, but how can teachers develop such environments and practices? There have been several programs and curricula developed based upon SDT and the research on autonomy-supportive teaching, including the Autonomy-Supportive Intervention Program (ASIP) and the Deeper Living Deeper Learning Curriculum.

\section{Autonomy-Supportive Intervention Program}

Based upon the research on autonomy-supportive classrooms and teachers, Reeve, Cheon, and colleagues developed ASIP, a teacher-focused, workshopcentred intervention program that aims to upgrade the quality of teachers' motivating styles and to develop their professions (Cheon, 2010; Cheon \& Lee, 2010; Cheon \& Moon, 2010; Cheon, Reeve, Lee, \& Lee, 2018; Cheon et al., 2019; Cheon, Reeve, \& Moon, 2012; Cheon, Reeve, \& Song, 2016, 2019; Cheon et al., 2020; Reeve \& Cheon, 2016; Reeve, Jang, Carrell, Jeon, $\&$ Barch, 2004). The main purpose of the ASIP is to enable teachers to become more autonomy-supportive and less controlling in their approach to teaching.

The program is delivered in three parts. The first part involves a threehour workshop-like experience. The session begins with a warm-up activity in which participants consider scenarios describing teachers who are either highly autonomy-supportive or highly controlling and reflect on which scenario might best illustrate their teaching style. Participants are then provided with a presentation on a SDT view of student motivation, teacher motivating styles (i.e., autonomy-supportive instructional behaviours and controlling instructional behaviours), and examples of autonomy-supportive 
instruction, along with supporting evidence. The first part concludes with a group discussion in which participants brainstorm how they might be able to engage in autonomy-supportive teaching styles in the classroom.

The second part occurs about six weeks later and lasts about three hours. The session begins with a brief presentation reviewing the features of autonomy-supportive teaching. Next, in small groups, teachers share and discuss about the autonomy-supportive teaching practices that they had implemented during the time in between the two sessions, including identifying concerns, obstacles, and successes. Next, teachers learn the "how to" of skills and strategies needed in supportive teaching. Through practical cases and examples, modelling, scaffolding, guidance, and feedback about practices engaged, teachers learn ways to present learning activities in an autonomy-supportive manner that identify, nurture, and vitalize students' inner motivational resources (i.e., autonomy, competence, and relatedness). Teachers also learn how to be need-supportive towards their students in their particular teaching activities, such as providing explanatory and meaningful rationales for requests and by taking students' perspectives.

In the third part, which is again about four to six weeks after the previous section, participants again engage in a group discussion, with this one focused exclusively on sharing ideas, practical experiences they have had since beginning the program, and further motivational strategies regarding ways to be autonomy-supportive in the instructional context and to develop classroom structures in an autonomy-supportive manner. For instance, this includes strategies for offering step-by-step guidance, providing new and corrective feedback, modelling, establishing classroom rules and expectations, reflecting on learning activities in students' perspective, using informational and nonepressurizing tone of speech, and providing meaningful rationales. In group discussions, teachers not only talk about their classroom teaching experiences in general but also share and develop their specific activity-by-activity and situation-by-situation teaching experiences, such as how to utilize autonomysupportive instructional strategies at both individual level, activity level (team games vs. individual games), and classroom level.

Cheon et al. (2018) found that the ASIP was effective not only in promoting student autonomy, but also in empowering teachers who implement these practices. They suggested that participation in ASIP "allows teachers to develop three empowering personal-professional resourcesnamely, greater psychological need satisfaction during teaching, efficacy, and the adoption of relatively more intrinsic (and less extrinsic) instructional goals" (p. 44). That is, teacher's implementing autonomy-supportive practices improve their own positive need satisfaction, gain a sense of efficacy, and feel 
more intrinsically motivated in the classroom and less controlled by external forces.

The ASIP research has consistently demonstrated three main effects. First, when teachers learned how to become autonomy supportive, students benefited from receiving autonomy support, compared to students in standard classrooms (Cheon \& Reeve, 2015; Cheon et al., 2012). The ASIP effects are sustained as teachers became even more autonomy-supportive over time (Cheon \& Reeve, 2013). Second, teachers involved in the ASIP reported greater job satisfaction as a teacher, greater passion to teach, greater subjective vitality, and less psychological ill-being from providing autonomy supports to their students, compared to teachers who were not part of the ASIP (Cheon et al., 2020; Cheon, Reeve, Yu, \& Jang, 2014). Finally, teachers who received the ASIP upgraded their classroom motivating styles, becoming more needsupportive, less need-indifferent, and less need-thwartive, and developed their professional resources, reporting greater need satisfaction, greater teaching efficacy, and more reliance on intrinsic goals to teach (Cheon et al., 2018; Reeve \& Cheon, 2016).

\section{The Deeper Living, Deeper Learning Curriculum}

Beyond training teachers to develop their classrooms and teaching styles to be more autonomy-supportive, specific curricula have been developed that explicitly aim to promote self-determination. One such curriculum is the Deeper Living, Deeper Learning Curriculum (Silver, 2020). The framework for the curriculum intentionally links with an aligned autonomy leadership approach aimed to sustainably enhance Reeve's (2002) social nutrients and cultural conditions that enhance self-determination, while being mindful of the biological factors of individual learners. The curriculum was developed to increase five key components that theoretically underpin the approach drawn from positive psychology and SDT:

1. Autonomy,

2. Competence,

3. Relatedness,

4. Meaning, and

5. Mastery.

Building from these dimensions, rather than forcing specific prescribed content, the curriculum provides structural prompts. This gives teachers and learners the opportunity to autonomously plot their volitional action 
and their individual and collective agentic actions that the curriculum structure and chosen qualifications ask of them, seeking to increase their self-determination over time (Chang, Adams, \& Little, 2017; Shogren et al., 2015). As part of the curriculum, teachers work with students to support them to choose a project on which they will work on across the semester (for approximately 350 hours during the year), increasing their competence along the way. In so doing, teachers promote autonomy by providing choices and by allowing students to select subjects, projects, and qualifications that are meaningful to them and on which they can be successful in pursuing future pathways. Teachers promote students' competence with weekly reflections supporting this, as well as meta-cognition. There are also twice-a-term exhibition days to celebrate and share with the community's stakeholders. Students are enabled to set their own learning pace, to identify individualized goals that they would work towards, and the process emphasized creating community amongst learners and teachers as well as connecting students with their communities outside of the school context.

Having to design and negotiate this process together supports stakeholder autonomy and relatedness, while forming project group identity and ownership of the agentic action. Group collaboration is common, enhancing relatedness among learners, peers, and teachers, as each person invests trust into the relationships and which are enhanced by shared responsibility in decisions and actions (Brockett \& Hiemstra, 2012). Raising learners' sense of self-accountability during decision making, guided by conversation about values, ego and moral maturity, steers learning behaviour to be mediated by action-control beliefs. Such responsibility is supported by the wellbeing components of the curriculum in that it enhances learners' ability to respond appropriately, through understanding communication, self-awareness, and self-regulation and their respective techniques (Chene, 1983). Purposeful increases to promote autonomy in target settings and sessions learners wished to attend impacted on engagement and outcomes.

The Deeper Living, Deeper Learning Curriculum has shown positive impact on student wellbeing, academic achievement, and destinations (Silver, 2020). Importantly, the curriculum has been implemented with students with disabilities, who are too often not addressed in positive education efforts. That, in turn, leads us to work in the field of special education to promote self-determined learning. 


\section{Promoting Self-Determined Learning}

The focus on autonomy-supportive classrooms and teaching driven by SDT has been primarily on the context in which students learn and the ways in which teachers interact with students. However, an important part of education involves students learning skills, knowledge, and abilities that enable them to be successful. To that end, efforts driven by Causal Agency Theory have been designed to teach skills related to causal agentic action and to promote student self-determination and self-determined learning. While various approaches have been developed, the most widely researched such intervention is the Self-Determined Learning Model of Instruction (SDLMI; Wehmeyer, Palmer, Agran, Mithaug, \& Martin, 2000).

The SDLMI provides teachers with a model that enables them to teach students to teach themselves. The SDLMI arose from causal agency theory, aiming to provide a teaching model to support student self-determined learning (Wehmeyer et al., 2000). Though developed initially with students with disabilities, the model has more recently been utilized with students with and without disabilities (Shogren, Wehmeyer, \& Lane, 2016), and has been used to support instruction across age ranges. Implementation of the SDLMI consists of a three-phase instructional process that is illustrated in Figs. 9.1, 9.2 and $9.3 .^{1}$

Each phase of the SDLMI presents a problem to be solved by the student, which the student does by answering a series of four student questions that they learn, modify to make their own, and apply to reach self-set goals. Each student question is linked to a set of teacher objectives, which in turn are linked to educational supports that can be used to teach or support students to answer the question and, thus, self-regulate problem-solving to set and attain goals. In each phase, as emphasized in Causal Agency Theory, the student is considered the causal agent for actions, including choice, decision making, and goal setting.

The student questions direct students through a problem-solving sequence, the solution to which leads to the problem in the next phase, and the problem-solving sequence is repeated. The problems to be solved are:

\footnotetext{
${ }^{1}$ A full description of the SDLMI process is beyond the scope of this chapter and is available in The self-determined learning model of instruction teacher's guide (Shogren, Raley, Burke, \& Wehmeyer, 2019), available at http://www.self-determination.org. The description here is a shortened version from this source.
} 


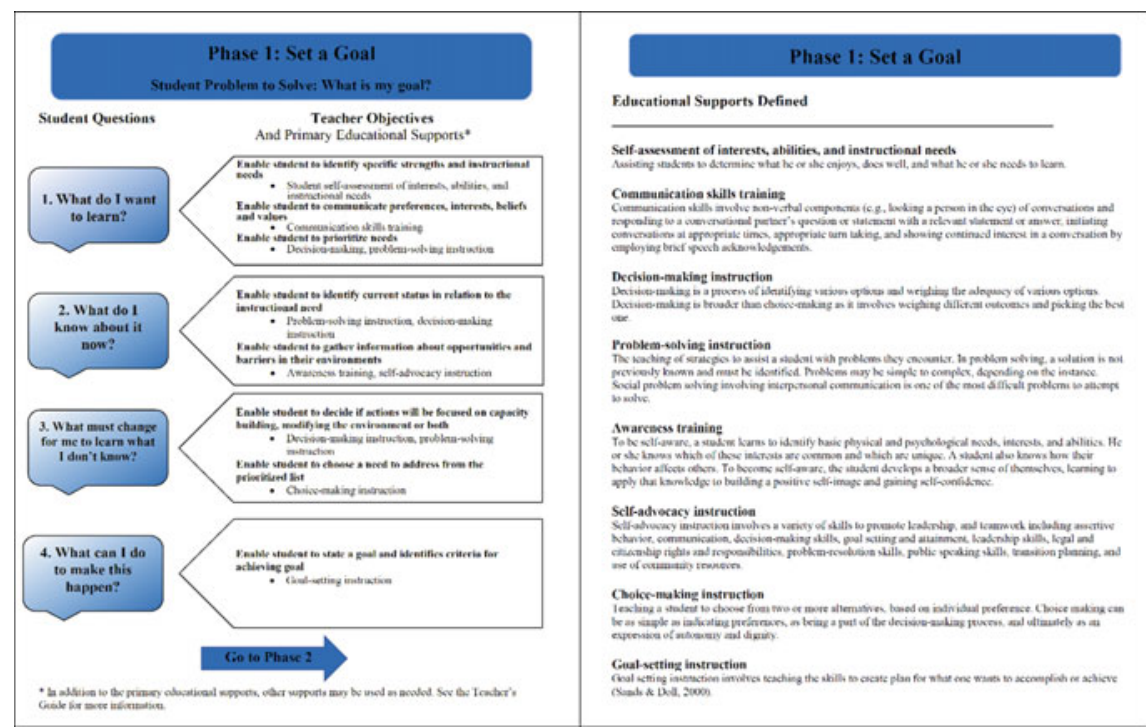

Fig. 9.1 Self-determined learning model of instruction Phase 1 (Original image published in Shogren, K. A., Raley, S. K., Burke, K. M., \& Wehmeyer, M. L. (2019). Teacher's guide to the self-determined learning model of instruction. http://wwwself-determination.org, by Kansas University Center on Developmental Disabilities. This image is licensed under an All Rights Reserved License, and is not available under a Creative Commons license)

- Phase 1-What is my Goal?

- Phase 2-What is my Plan?

- Phase 3-What have I Learned?

The four questions in each phase are worded differently to enable the student to solve the unique problem posed in each phase, but in each phase, the four questions represent identical steps in a problem-solving sequence:

(1) identify the problem,

(2) identify potential solutions to the problem,

(3) identify barriers to solving the problem, and

(4) identify consequences of each solution.

The SDLMI is an instructional model, and so it is designed for teachers to implement and, as such, the student questions are worded so that teachers understand the intent of the question. Thus, the first time a teacher uses the model with a student, the teacher can read each question with or (if necessary) to the student, talk about what the question means with the student, and, 


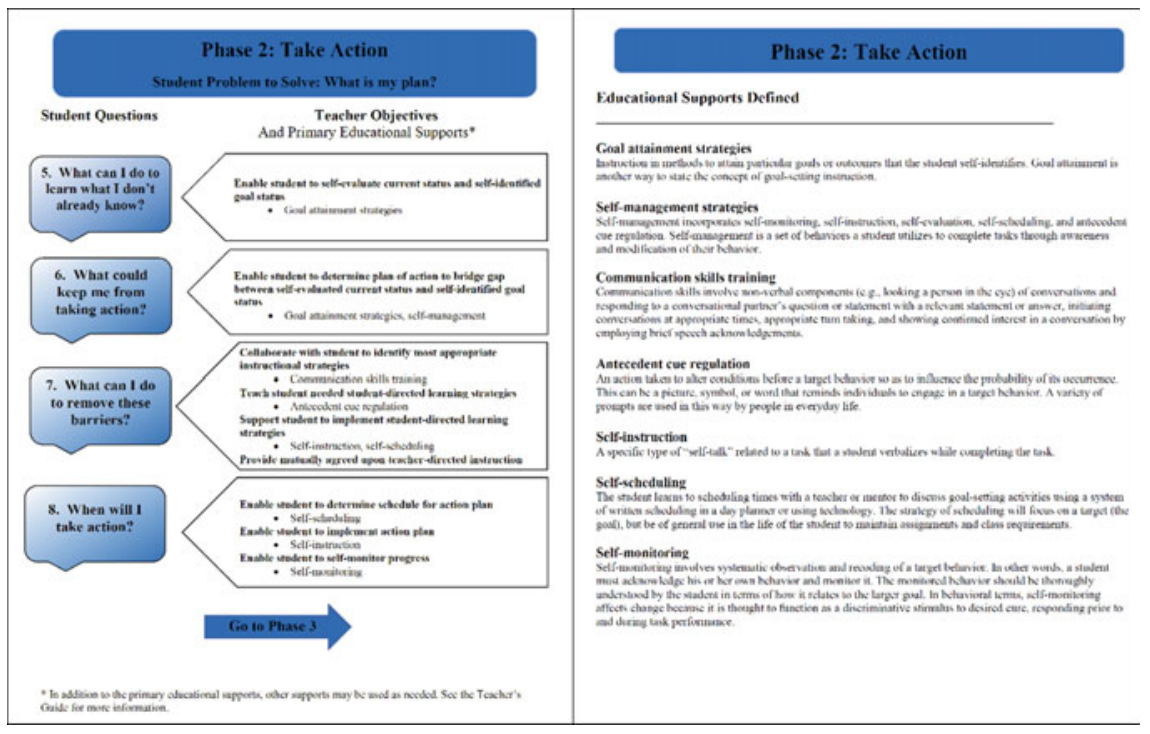

Fig. 9.2 Self-determined learning model of instruction Phase 2 (Original image published in Shogren, K. A., Raley, S. K., Burke, K. M., \& Wehmeyer, M. L. (2019). Teacher's guide to the self-determined learning model of instruction. http://wwwself-determination.org, by Kansas University Center on Developmental Disabilities. This image is licensed under an All Rights Reserved License, and is not available under a Creative Commons license)

if it is the student's preference, to reword the question so that student can understand the intent. By the time a teacher and student go through the model once, students will have a set of questions that are their own.

The teacher objectives provide specific information to teachers on what they need to support students to do when answering a question. The teacher objectives provide a road map for the teacher to enable students to solve the problem stated in the student question. For example, with the first student question (what do I want to learn?), the teacher objectives are to enable the student to identify his/her specific strengths and instructional needs related to the content area, identify and communicate his/her preferences, interests, beliefs, and values about the content area and its link to adult outcomes, and prioritize his/her instructional needs.

Each teacher objective is linked to at least one educational support. So, for example, the final question in the first phase prompts students to set an educational goal. If they have not had prior experience with goal setting, they will need instruction to do so, and as such, goal setting and attainment instruction is an educational support associated with that question. 


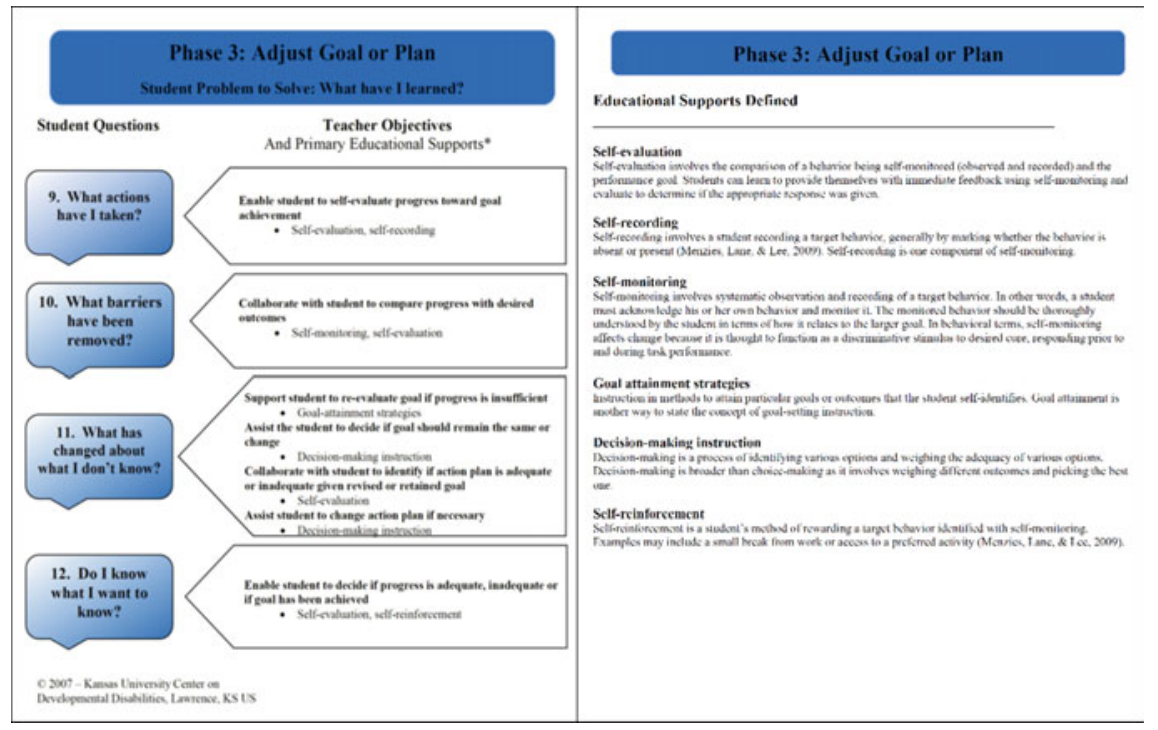

Fig. 9.3 Self-determined learning model of instruction Phase 3 (Original image published in Shogren, K. A., Raley, S. K., Burke, K. M., \& Wehmeyer, M. L. (2019). Teacher's guide to the self-determined learning model of instruction. http://wwwself-determination.org, by Kansas University Center on Developmental Disabilities. This image is licensed under an All Rights Reserved License, and is not available under a Creative Commons license)

Most of these supports are identified from the self-management and selfdirected learning literature. Since the purpose of the SDLMI is to enable teachers to teach students to self-directed and self-determine learning, it makes sense that teachers should enable students to use self-management and self-regulation strategies that enable them self-direct learning. But not every instructional strategy is student directed. The purpose of a teaching model is to promote student learning. Sometimes the most effective method or strategy to achieve an educational outcome will be a teacher-directed strategy. Within the SDLMI context, students are active in determining these educational plans, whether self- or teacher-directed.

There is strong evidence to support the efficacy of the SDLMI, including randomized trial studies conducted in the United States have established causal relationships between implementing the SDLMI and more positive student self-determination and school and adult outcomes (Wehmeyer, Shogren, Little, \& Lopez, 2017). Though primarily evaluated with students with disabilities, the SDLMI is not a disability-specific intervention and largescale studies are underway that are evaluating the impact of the SDLMI as implemented for all students in high school Language Arts and Algebra 
classes. Combined with autonomy-supportive teaching and classroom strategies, the SDLMI provides educators with a means to teach students to self-regulate problem-solving to set and attain educational goals, adjusting their goals and plans as necessary. In other words, the SDLMI enables young people to be causal agents in their lives and to act to attain basic psychological needs for autonomy and competence.

\section{Conclusion}

Importantly, issues of self-determination and self-determined learning are at the heart of personalized education and twenty-first-century learning (Wehmeyer \& Zhao, 2020). Learning in twenty-first-century schools should be characterized by student voice in school governance and environment, student choice in a broad and flexible curriculum, and a strengths-based focus on student uniqueness and curiosity (Zhao, 2012). It is clear that to prepare young people for the twenty-first-century world, among the most important things we can do is to promote self-determination and self-determined learning, emphasize goal setting and problem-solving, and consider student strengths and support students to design a life based on those strengths, interests, and abilities (Wehmeyer \& Zhao, 2020).

Zhao (2018) suggested that the educational status quo is a system that is based upon two flawed assumptions: (1) that "there is a set of skills and knowledge everyone must have in order to live a successful life in the world" and (2) that "all children are capable of and interested in acquiring the skills and knowledge at a similar pace" (p. 8). He argues that understandings of human nature and learning suggest that human beings are differently talented, have different desires and interests, and have different experiences that interact with their natural talents and interests to give each person a unique profile of abilities and desires, stronger in some areas and weaker in others, and that in such a context, there is no utility to notions of "average". To create schools that benefit all students, we need to focus on promoting student agency, student ownership over learning, and emphasize meaningfulness and purpose.

Student agency is more than just students' having a voice in what happens, but instead, is about students being, as Zhao (2018) noted, "owners of their own learning ... they must have agency in designing their own learning" (p. 58). Student agency is central to positive education, personalized learning, and twenty-first-century education. Students become agents in their own learning through the arrangements of environments and contexts to be 
autonomy-supportive and engaging in autonomy-supportive interactions and promoting self-determined learning, as has been discussed in this chapter. Student agency and ownership over learning are, it could be argued, at the heart of positive education.

\section{References}

Adams, N., Little, T. D., \& Ryan, R. M. (2017). Self-determination theory. In M. L. Wehmeyer, K. A. Shogren, T. D. Little, \& S. J. Lopez (Eds.), Development of self-determination through the life-course (pp. 47-54). New York: Springer.

Blaschke, L. M. (2012). Heutagogy and lifelong learning: A review of heutagogical practice and self-determined learning. The International Review of Research in Open and Distance Learning, 13, 56-71.

Brockett, R., \& Hiemstra, R. (2012). Reframing the meaning of self-directed learning. Proceedings of the Adult Education Research Conference (pp. 155-162). https://www.semanticscholar.org/paper/Reframing-the-Meaning-of-Self-Dir ected-Learning\%3A-An-Hiemstra-Brockett/a831600fb05c0dc8dacdc23208f4c5 $5 \mathrm{a} 0 \mathrm{c} 80 \mathrm{a} 995$.

Candy, P. C. (1992). Self-direction for lifelong learning. San Francisco, CA: JosseyBass.

Center on Addiction. (2003). CASA 2003 teen survey: High stress, frequent boredom, too much spending money: Triple threat that hikes risk of teen substance abuse. https://www.centeronaddiction.org/newsroom/press-releases/2003-teen-survey.

Chang, R., Adams, N., \& Little, T. (2017). Action-control beliefs and agentic actions. In M. L. Wehmeyer, K. A. Shogren, T. D. Little, \& S. J. Lopez (Eds.), Development of self-determination through the life-course (pp. 285-295). New York: Springer.

Chang, R., Fukuda, E., Durham, J., \& Little, T. D. (2017). Enhancing students' motivation with autonomy-supportive classrooms. In M. L. Wehmeyer, K. A. Shogren, T. D. Little, \& S. J. Lopez (Eds.), Development of self-determination throughout the life-course (pp. 99-110). New York: Springer.

Chene, A. (1983). The concept of autonomy in adult education: A philosophical discussion. Adult Education Quarterly, 1, 38-47.

Cheon, S. H. (2010). The effects of providing rationales in autonomy-supportive ways upon the identified regulation and intention of amotivated students toward physical activity. Korean Journal of Sport Psychology, 21, 309-326.

Cheon, S. H., \& Lee, Y. (2010). Effects of autonomy support intervention implemented in inclusive physical activity on basic psychological needs and behavioral: Emotional engagement of middle school students. The Journal of Special Children Education, 12, 201-221. 
Cheon, S. H., \& Moon, I. S. (2010). Implementing autonomy-supportive fitness program to facilitate students' autonomy and engagement. Korean Journal of Sport Psychology, 21, 175-195.

Cheon, S. H., \& Reeve, J. (2013). Do the benefits from autonomy-supportive PE teacher training programs endure? A one-year follow-up investigation. Psychology of Sport and Exercise, 14, 508-518.

Cheon, S. H., \& Reeve, J. (2015). A classroom-based intervention to help teachers decrease students' amotivation. Contemporary Educational Psychology, 40, 99-111.

Cheon, S. H., Reeve, J., \& Moon, I. S. (2012). Experimentally-based, longitudinally designed, teacher-focused intervention to help physical education teachers be more autonomy supportive toward their students. Journal of Sport \& Exercise Psychology, 34, 365-396.

Cheon, S. H., Reeve, J., Lee, Y., \& Lee, J.-W. (2018). Why autonomy-supportive interventions work: Explaining the professional development of teachers' motivating style. Teaching and Teacher Education, 69, 43-51.

Cheon, S. H., Reeve, J., Lee, Y., Ntoumanis, N., Gillet, N., Kim, B. R., et al. (2019). Expanding autonomy psychological need states from two (satisfaction, frustration) to three (dissatisfaction): A classroom-based intervention study. Journal of Educational Psychology, 111, 685-702.

Cheon, S. H., Reeve, J., \& Song, Y.-G. (2016). A teacher-focused intervention to decrease PE students' amotivation by increasing need satisfaction and increasing need frustration. Journal of Sport \& Exercise Psychology, 38, 217-235.

Cheon, S. H., Reeve, J., \& Song, Y.-G. (2019). Recommending goals and supporting needs: An intervention to help physical education teachers communicate their expectations while supporting students' psychological needs. Psychology of Sport and Exercise, 41, 107-118.

Cheon, S. H., Reeve, J., Yu, T. H., \& Jang, H.-R. (2014). The teacher benefits from giving autonomy support during physical education instruction. Journal of Sport and Exercise Psychology, 36, 331-346.

Cheon, S. H., Reeve, J., \& Vansteenkiste, M. (2020). When teachers learn how to provide classroom structure in an autonomy-supportive way: Benefits to teachers and their students. Teaching and Teacher Education, 90,

DeCharms, R. (1968). Personal causation: The internal affective determinants of behavior. New York: Academic Press.

Deci, E. L., Ryan, R. M., \& Guay, F. (2013). Self-determination theory and actualization of human potentials. In D. M. McInerney, H. W. Marsh, R. G. Craven, F. Guay, \& D. M. McInerney (Eds.), Theory driving research: New wave perspectives on self-processes and human development (pp. 109-133). Charlotte, NC: Information Age Publishing.

Deci, E. L., \& Vansteenkiste, M. (2004). Self-determination theory and basic need satisfaction: Understanding human development in positive psychology. Ricerche di Psichologia, 27, 17-34. 
Frederic, G., Ratelle, C. F., \& Chanal, J. (2008). Optimal learning in optimal contexts: The role of self-determination in education. Canadian Psychology, 49(3), 233-240.

Gallup Youth Survey. (2004). Most teens associate school with boredom, fatigue. https://news.gallup.com/poll/11893/most-teens-associate-school-boredom-fat igue.aspx.

Grolnick, W. S., \& Pomerantz, E. M. (2009). Issues and challenges in studying parental control: Toward a new conceptualization. Child Development Perspectives, 3, 165-170.

Jason, Z. (2017, Winter). Bored out of their minds: A look at why students get increasingly bored as they get older-and why it matters. Harvard Education Magazine. https://www.gse.harvard.edu/news/ed/17/01/bored-out-their-minds.

Knowles, M. S. (1975). Self-directed learning: A guide for learners and teachers. Chicago, IL: Follett Publishing Co.

Little, T. D., Hawley, P. H., Henrich, C. C., \& Marsland, K. (2002). Three views of the agentic self: A developmental synthesis. In E. L. Deci \& R. M. Ryan (Eds.), Handbook of self-determination research (pp. 389-404). Rochester, NY: University of Rochester Press.

Mouratidis, A., Lens, W., \& Vansteenkiste, M. (2010). How you provide corrective feedback makes a difference: The motivating role of communicating in an autonomy-supporting way. Journal of Sprot \& Exercise Psychology, 32, 619-637.

Mumbardó-Adam, C., Guàrdia-Olmos, J., \& Giné, C. (2018). Assessing selfdetermination in youth with and without disabilities: The Spanish version of the AIR self-determination scale. Psicothema, 30(2), 238-243.

Niemiec, C. P., \& Ryan, R. M. (2009). Autonomy, competence, and relatedness in the classroom: Applying self-determination theory to educational practice. Theory and Research in Education, 7(2), 133-144.

Reeve, J. (2002). Self-determination theory applied to educational settings. In E. L. Deci \& R. M. Ryan (Eds.), Handbook of self-determination research (pp. 183203). Rochester, NY: Rochester University Press.

Reeve, J. (2012). A self-determination theory perspective on student engagement. In S. L. Christenson, A. L. Reschly, \& C. Wylie (Eds.), Handbook of research on student engagement (pp. 149-172). New York, NY: Springer.

Reeve, J., \& Cheon, S. H. (2014). An intervention-based program of research on teachers' motivating styles. In S. Karabenick \& T. Urdan's (Eds.), Advances in motivation and achievement: Motivational interventions (Vol. 18, pp. 293-339). Bingley, UK: Emerald Group Publishing.

Reeve, J., \& Cheon, S. H. (2016). Teachers become more autonomy supportive after they believe it is easy to do. Psychology of Sport and Exercise, 22, 178-189.

Reeve, J., \& Cheon, S. H. (2020). Sociocultural influences on teachers' reactions to an intervention to help them become more autonomy supportive. In G. A. D. Liem \& D. M. McInerney (Eds.), Promoting motivation and learning in contexts: Sociocultural perspectives on educational interventions (pp. 13-36). Information Age Publishing. 
Reeve, J., Jang, H., Carrell, D., Jeon, S., \& Barch, J. (2004). Enhancing high school students' engagement by increasing their teachers' autonomy support. Motivation and Emotion, 28, 147-169.

Reeve, J., Ryan, R. M., \& Deci, E. L. (2018). Sociocultural influences on student motivation as viewed through the lens of self-determination theory. In D. M. McInerney \& G. A. D. Liem (Eds.), Big theories revisited 2: Research on sociocultural influences on motivation and learning (pp. 15-40). Greenwich, CT: Information Age Publishing.

Ryan, R. M., \& Deci, E. L. (2017). Self-determination theory: Basic psychological needs in motivation, development, and wellness. New York: The Guilford Press.

Shogren, K. A., Raley, S. K., Burke, K. M., \& Wehmeyer, M. L. (2019). Teacher's guide to the self-determined learning model of instruction. Lawrence, KS: Kansas University Center on Developmental Disabilities. http://www-self-determinatio n.org.

Shogren, K. A., Wehmeyer, M. L., \& Lane, K. L. (2016). Embedding interventions to promote self-determination within multi-tiered systems of supports. Exceptionality, 24(4), 213-244.

Shogren, K. A., Wehmeyer, M. L., Palmer, S. B., Forber-Pratt, A., Little, T., \& Lopez, S. (2015). Causal agency theory: Reconceptualizing a functional model of self-determination. Education and Training in Autism and Developmental Disabilities, 50(3), 251-263.

Silver, M. (2020). The deeper living, deeper learning curriculum. Harrow, UK: Shaftesbury High School. https://www.shaftesbury.harrow.sch.uk/Overview/.

Vansteenkiste, M., Niemiec, C. P., \& Soenens, B. (2010). The development of the five mini-theories of self-determination theory: An historical overview, emerging trends, and future directions. In T. C. Urdan \& S. A. Karabenick (Eds.), The decade ahead: Theoretical perspectives on motivation and achievement (advances in motivation and achievement, vol. 16 part A, pp. 105-165). Bingley, UK: Emerald Group Publishing.

Wehmeyer, M. L. (1992). Self-determination and the education of students with mental retardation. Education and Training in Mental Retardation, 27, 302-314.

Wehmeyer, M. L. (2004). Beyond self-determination: Causal agency theory. Journal of Developmental and Physical Disabilities, 16, 337-359.

Wehmeyer, M. L., Kelchner, K., \& Richards, S. (1996). Essential characteristics of self-determined behavior of individuals with mental retardation. American Journal on Mental Retardation, 100, 632-642.

Wehmeyer, M. L., \& Mithaug, D. (2006). Self-determination, causal agency, and mental retardation. In L. M. Glidden (Series Ed.) \& H. Switzky (Vol. Ed.), International review of research in mental retardation: Vol. 31 current perspectives on individual differences in personality and motivation in persons with mental retardation and other developmental disabilities (pp. 31-71). San Diego, CA: Academic Press. 
Wehmeyer, M. L., Palmer, S., Agran, M., Mithaug, D., \& Martin, J. (2000). Promoting causal agency: The self-determined learning model of instruction. Exceptional Children, 66, 439-453.

Wehmeyer, M. L., Shogren, K. A., Little, T. D., \& Lopez, S. J. (2017). Development of self-determination through the life-course. New York: Springer.

Wehmeyer, M. L., \& Zhao, Y. (2020). Teaching students to become self-determined learners. Alexandria, VA: ASCD.

Zhao, Y. (2012). World class learners: Educating creative and entrepreneurial students. Thousand Oaks, CA: Corwin Press.

Zhao, Y. (2018). Reach for greatness: Personalizable education for all children. Thousand Oaks, CA: Corwin.

Open Access This chapter is licensed under the terms of the Creative Commons Attribution 4.0 International License (http://creativecommons.org/licenses/by/4.0/), which permits use, sharing, adaptation, distribution and reproduction in any medium or format, as long as you give appropriate credit to the original author(s) and the source, provide a link to the Creative Commons license and indicate if changes were made.

The images or other third party material in this chapter are included in the chapter's Creative Commons license, unless indicated otherwise in a credit line to the material. If material is not included in the chapter's Creative Commons license and your intended use is not permitted by statutory regulation or exceeds the permitted use, you will need to obtain permission directly from the copyright holder.

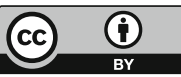

